\title{
MOUTH DISINFECTION IN THE PROPHYLAXIS AND TREATMENT OF PNEUMONIA.*†
}

A UGUSTUS WADSWORTH,

\begin{abstract}
Alonzo Clark Scholar in Pathology; Instructor in Bacteriology and Hygiene, College of Physicians and Surgeons, Columbia University; Assistant Physician to the Roosevelt Hospital, Out-Patient Department.
\end{abstract}

(From the Department of Pathology, College of Physicians and Surgeons, Columbia University.)

\section{INTRODUCTION.}

MoutH cleansing has long been practiced, but the full significance of it has been recognized only in recent years since it has been known that the secretions of the mouth contain large numbers of bacteria; some pathogenic and such as give rise to serious infectious processes, others non-pathogenic but associated with deleterious changes affecting the teeth and other tissues. Further study has now shown that virulent bacterial species are present in the secretions of healthy as well as diseased individuals, and not occasionally, but frequently. Thus as a means of controlling the spread of this infectious material, mouth cleansing has come to be more and more seriously considered, not only by physicians, but by the educated public. Recently, in the hope of securing disinfection, simple cleansing has to a large extent been replaced by a variety of antiseptic procedures which have been adopted without much definite knowledge of their efficiency. The general problem has been studied, but these researches, for the most part conducted with faulty technic or based solely on clinical observation, have not, except in diphtheria, been applied specifically to the study of different diseases. Accordingly, to determine the practical value of mouth disinfection in the prophylaxis and treatment of pneumococcus infection, these studies were undertaken in the hope of securing accurate data of specific import, and thus of being able to discriminate definitely between the more efficient and the inefficient, even harmful, procedures of which many have been widely recommended and are extensively used.

* Received for publication August 6, 1906 .

$\dagger$ This study was carried on under the auspices of the Medical Commission for the Investigation of Acute Respiratory Diseases of the Department of Health of the City of New York. 
THE PRACTICAL PROBLEM OF MOUTH DISINFECTION.

The bacteria of the mouth are continually changing;* large numbers are swallowed; others are thrown off in expectoration, and still others degenerate in the secretions or are taken up by the phagocytes and destroyed. On the other hand, the supply is being constantly replenished from the inspired air and ingested food, by the drainage of the nares and larynx through the mouth and pharynx, and also by the growth of species which develop in this environment.

The mucous membrane and anatomical arrangement of the mouth and pharynx are well adapted for the elimination of many of the bacterial species which gain access to the secretions, but which are unable to develop in this unfavorable environment. They are also equally well adapted for the protection and harboring of certain other species which grow and become established in the secretions as harmless parasites. $\dagger$ It is these bacteria, usually pathogenic although of varying grades of virulence, which are the most serious menace to health and the most troublesome in the attempts at mouth disinfection.

In the nares conditions are similar to those of the mouth, but the nasal secretion is chiefly mucus, and is rarely diluted with food or drink or by other secretions. Apparently harmless parasitism occurs less frequently in these secretions. $\$$ In the trachea, the secretions are practically pure mucus; and bacteria disappear with astonishing rapidity. It would thus appear that aside from many significant, but for present purposes indeterminate, conditions affecting the elimination, development, or protection of bacteria in this as in other parts of the body, mucus is peculiarly important.

* Rose's ${ }^{3 x}$ observations show the fluctuations under normal conditions during the 24 hours; the largest number of bacteria were found before breakfast, after the night's quiet; the smallest number after each meal; following this a gradual increase up to the next meal.

$+\mathrm{Netter}^{24}$ demonstrated the presence of pneumococci in the mouths of pneumonia patients 1o or more years after recovery, and found these organisms much more frequently in cases which gave a history of pneumonia.

ఫWitness, for example, the researches of Thomson and Hewlett, ${ }^{36}$ who determined experimentally the rapid disappearance of the bacteria deposited on the nasal mucous membrane. Neumann'25 was able to find pneumococci in the nasal secretion of only 4 per cent of the normal cases examined, whereas in the mouth, observers have rarely failed to obtain these organisms in at least 20 per cent of the normal cases. von Besser's ${ }^{3}$ comparative results also confirm these findings. 
Fresh mucus* has uniformly proved in the experience of several observers, distinctly bactericidal, and it is significant that the mucous membranes $\dagger$ which have a pure mucous secretion are usually free from microorganisms although they are more or less exposed to contamination. Furthermore, mucus diffuses slowly with foreign material and as a natural bland protection to the mucous membrane there is no adequate substitute. In the nares, pharynx, trachea, and mouth, irritation of the mucous membrane is immediately followed by an outpouring of fresh mucus; a flushing from within outward by a natural secretion which apparently meets all the requirements of an ideal wash.

Thus it is that the natural resources of the tissues under normal conditions are extremely well adapted for the protection of the individual carrying virulent pathogenic bacteria in the mouth as harmless parasites. One may well hesitate before disturbing this nice and well-perfected arrangement of nature, but conditions arise in disease when it is evident that these natural resources may be greatly aided in re-establishing the normal equilibrium between the bacteria on the one hand and the susceptibility of the tissues on the other. And then, although for the time being themselves adequately protected, healthy individuals if they carry about in their secretions dangerous bacteria, may become a menace to their fellows.

In the attempt to aid the natural resources of the tissues in the elimination of infectious material by mouth cleansing or disinfection, there are several factors which render the problem both serious and difficult. The mucus which protects the mucous membrane from the bacteria also protects the bacteria from the action of foreign substances. The removal of mucus exposes the mucous membrane to more or less irritation which may be accompanied by exudation, development of the bacteria remaining in the secre-

* In the studies of Wurtz and Lemoye ${ }^{43}$ with sputum, of Walthard ${ }^{37}$ and of Stroganoff ${ }^{34}$ with cervical secretion, and of Arloing ${ }^{5}$ with the secretion of mussels, the bactericidal qualities of mucus have been determined in vitro. Grawitz, ${ }^{33}$ Steffen, ${ }^{33}$ and also Hopkins, ${ }^{15}$ failed to detect this action, but in their studies the material was sterilized by heat. Recently, Wood $4^{\circ}$ found that pneumococci were much more quickly destroyed in mucus than in sputum.

$\dagger$ The uterine and the greater portion of the urethral and bronchial mucous membranes on careful examination have usually under normal conditions proved sterile. The introduction of bacteria in the animal experimentation of Morisani2 ${ }^{3}$ on the uterus, of $\mathrm{Beco}^{2}$ and others on the respiratory tract, was followed under normal conditions by a rapid disappearance of these organisms. My own experiments with the pneumococcus in the respiratory tract indicate that these organisms under normal conditions disappear from the tracheal and bronchial mucous membranes of rabbits with astonishing rapidity. 
tions with increase of virulence, and possibly infection. Many antiseptics are irritants and in the mouth of doubtful disinfecting value. Solutions to be used in the mouth and pharynx should therefore be selected with care and should possess certain essential qualities. In general, they should be bland to the mucous membranes, diffuse quickly with the secretions, and, if antiseptic, should be of known practical value.

Most observers in recent years advise approximately neutral reactions for mouth washes. Acids have been used. Bacteria in the fermentation of sugars form acid rapidly and when certain percentages are reached growth stops and some species, especially the pneumococci, die rapidly. On the other hand, caries of the teeth Miller $^{20}$ has shown to be largely due to the acid fermentation of sugars in the mouth by bacteria,* and it is now deemed better to neutralize whatever acid may be present rather than to introduce any more. Alkalis have also been recommended, chiefly on account of the more rapid diffusion with the secretions, but they have little or no action on the bacteria in strengths which can be used with comfort in the mouth. On the gums and teeth they are generally considered injurious. The reaction of solutions to be used in the mouth should therefore be neutral or preferably slightly alkaline to neutralize whatever acid may be present.

Since many of the complicated solutions fail to do more than remove the contaminated secretion, the use of plain water has been recommended. The body fluids and particularly those containing mucus, do not, however, diffuse well with water and the tissue cells undergo varying degrees of plasmolysis. Although these are not serious objections to the use of water in the mouth, better results it is well known may be secured if the water be made isotonic by the addition of salts.

Antiseptics obviously should be not only efficient in destroying the bacteria, but bland to the mucous membrane, and if by chance swallowed or absorbed, harmless to the individual. The choice is thus limited. Nevertheless a great variety of antiseptics have been recommended by different observers. When such diversity

\footnotetext{
* The recent investigations of Monier $^{22}$ and of Rodella ${ }^{30}$ suggest that anaerobic bacteria are largely responsible for this sugar fermentation.
} 
of opinion exists and when similar results are secured by different procedures, the efficiency of the antisepsis may be seriously questioned. In fact, the researches conducted in the New York Health Department under Dr. Park showed that in a long series of diphtheria cases the best results were secured by cleansing the mouth with simple normal salt solution.

In the early experiments of Miller, ${ }^{21}$ and in the recent studies of Rose, ${ }^{31}$ portions of the mucous membrane were cleansed and remained sterile for a few minutes; but it was impossible even to approximate complete disinfection of the mouth with any of the long list of antiseptics tested. Miller ${ }^{21}$ recommended bichloride solutions. Rose ${ }^{3 x}$ condemned them and recommended in turn 60 per cent alcohol used with a brush as the most efficient antiseptic in the mouth: Other observers apparently have obtained excellent results with alcohol and advise its use in the mouth, but not stronger than 30 per cent, because in higher percentages its continued use desiccates and hardens the tissues. Although the antiseptic value of alcohol has long been recognized,* it may be of interest to note in this connection that students of hand disinfection $\dagger$ have recently come to look upon it as one of the most useful and efficient disinfectants employed in solving the intricate and difficult problems encountered in this field of investigation. The unsubstantiated claims and recommendations of other observersł concerning other antiseptics, many of which have already proved in Miller's or Rose's experiments inefficient, might be cited, but to no purpose.

It thus appears that the results of former studies agree in but one particular, that complete disinfection of the mouth is impossible. With the methods employed no discrimination can be made between the part played by normal physiological processes aided by simple cleansing and the part played by antiseptics in the elimination of bacteria. Obviously, the antiseptics could not be expected to accomplish the impossible, but apparently no adequate effort was made to determine their action under favorable conditions, and in view of the conflicting results, the varied recommendations, and the

* For recent studies see the work of Weigl ${ }^{8}$ and Wirgin. ${ }^{39}$

† Witness, for example, the researches of Engels, ${ }^{8}$ Flecksedor, ${ }^{10}$ Shaffer, ${ }^{32}$ Sturtz,, 35 Bonhoff,5 Danielshon and Hess.?

$\ddagger$ Vide, Beck in Kolle and Wassermann, ${ }^{, 6}$ also Ritter, ${ }^{29}$ Miller, ${ }^{2 x}$ Rose, ${ }^{3 x}$ and Grewe. ${ }^{13}$ 
substantial support given simple measures, it might well be assumed that many of the experiments were conducted with solutions antiseptic in name only or in lower dilutions.

\section{THE PRACTICAL PROBLEM OF MOUTH DISINFECTION IN PNEUMONIA.}

The problem of getting rid of the pneumococci in the secretions of the mouth is beset with even greater difficulties. With the possible exception of the streptococci, the pneumococci of all the pathogenic bacteria are most apt to become established as harmless parasites. Extremely susceptible to environmental change, and readily adapting itself to grow in serous exudates, the pneumococcus often rapidly acquires an exalted virulence. In the mouth the secretions are often diluted and contain nutrient material; and the pneumococci develop and persist under these conditions to such an extent that they are to be found in some individuals constantly, in others frequently, and in crowded communities at one time or another in nearly everyone.* In the purely mucous secretions of the healthy intact mucous membranes the pneumococci, like other species of bacteria, do not long survive. It is thus probable that comparatively few of the pneumococci develop in the glandular openings where the fresh mucous secretions are continually being poured out. The folds of mucous membrane about the teeth and tonsils, and in other inaccessible places, on the other hand, doubtless harbor considerable numbers of these organisms. $\dagger$

Under these conditions and in the light of the experience of previous observers, it might reasonably be inferred that the problem of securing the elimination of the pneumococcus is quite as impossible as that of complete disinfection. Nevertheless, by securing a mouthwash of definite antiseptic value, and then by continually removing and destroying the pneumococci in the more accessible parts of the mouth, it was hoped and thought possible that in healthy individuals at least the outpouring of fresh secretion might gradually replace the contaminated secretion until finally few, if any, pneumo-

* The results of Park and Williams, ${ }^{27}$ Longcope and Fox, ${ }^{18}$ Buerger, ${ }^{6}$ and Hiss ${ }^{4}$ are of particular significance as they suggest the conditions prevailing in our large cities during the winter months.

$\dagger$ Bezançon and Griffon ${ }^{\mathrm{r}}$ on scraping the mucous membranes of the tonsil found pneumococci in roo per cent of the cases examined, exceptional results as compared with those obtained in examinations of other observers. 
cocci remained. But the first step was to determine accurately and from a practical view-point the most efficient solution to be used in the mouth. This, it may be recalled, should react neutral or slightly alkaline, diffuse rapidly with the secretions, and be isotonic and bland to the mucous membranes, and not poisonous. Finally, if antiseptic, it should also and above all be efficient.

Antiseptics vary in their mode of action: some combine chemically with the bacterial cell or coagulate the proteids; others give rise to plasmolytic changes. The pneumococcus, it was thought, owing to its albuminous capsule, and its great susceptibility to change of environment as compared with other species of bacteria, might differ in its susceptibility to these different antiseptics. It was accordingly deemed wise to determine first the comparative susceptibility of different pathogenic bacteria to plasmolysis, and then secure accurate data regarding the action of various antiseptic solutions on the pneumococcus under different conditions. Finally, a study of the practical value of the most efficient of the antiseptic solutions as compared with that of simple isotonic salt solution, was conducted on healthy individuals whose secretions contained virulent pneumococci, and on pneumonia patients.

\section{PLASMOLYSIS OF PATHOGENIC BACTERIA IN SODIUM CHLORIDE SOLUTION.}

For comparison with the pneumococcus, the bacilli of diphtheria, anthrax, pneumonia (Friedländer), and typhoid, the vibrio of cholera, and Staphylococcus pyogenes aureus, were selected. From 24 hour agar cultures of these organisms, broth emulsions were made and $\frac{1}{20}$ c.c. transferred to test-tubes containing 2 c.c. of the various salt solutions.* The appearance of the tubes was noted at stated intervals. At the same time definite quantities were plated in agar and counted after 24 or 48 hours' incubation. The results of this experiment appear in the following table:

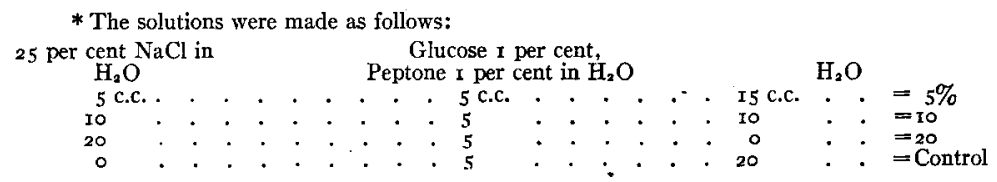


Mouth Disinfection in Pneumonia

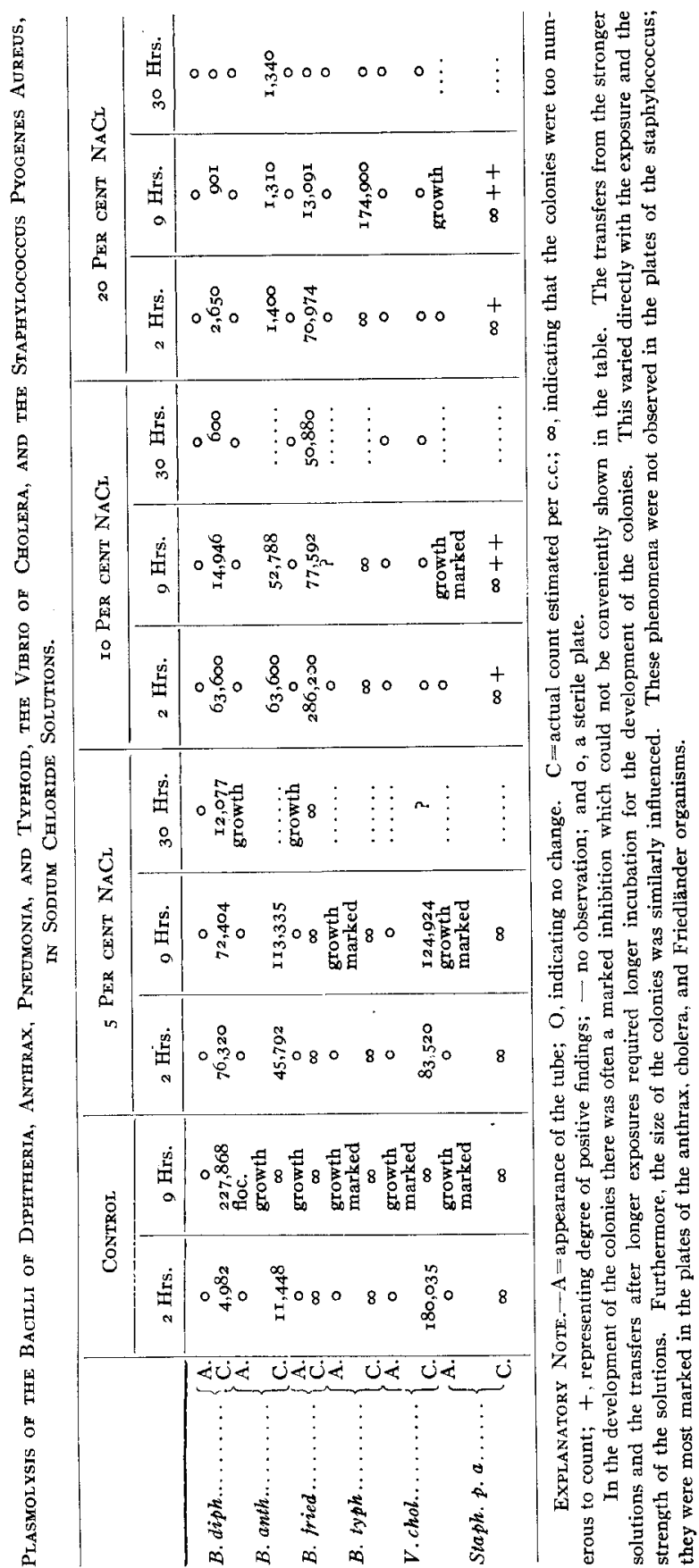


These tests suffice to indicate the wide differences in the susceptibility to the plasmolysis of sodium chloride solutions that may exist among different species of pathogenic bacteria.* The insusceptibility of anthrax spores is shown by the constant figures obtained in the counts from the strong 20 per cent solutions. On the other hand, anthrax vegetative cells, quickly destroyed in the 20 per cent solutions, showed slight development in the Io per cent solutions, and were thus slightly more susceptible than the diphtheria bacilli, and considerably more so than the Friedländer and typhoid organisms. The staphylococcus, which was little affected by the 20 per cent solutions, proved the most resistant. The cholera vibrio, quickly destroyed in the Io per cent solutions, was the most susceptible. Attention may also be directed to the fact that although the Friedländer organism is an encapsulated cell, similar to the pneumococcus, it was one of the least susceptible to plasmolysis.

In the experiments with the pneumococcus, definite quantities from the tests were not plated in agar and counted as in the experiments with the other species of bacteria. The method is particularly unfavorable for the growth of the pneumococcus and many cells fail to develop under these conditions. Streaking the surface of serum agar offers the most favorable conditions for the growth of the pneumococcus. As this method was considered a more reliable and significant test of complete disinfection, it was adopted in all the following experiments. In the simple glucose peptonewater media used in making the solutions of the previous experiments, the pneumococcus would not grow. A more favorable meat infusion broth was therefore substituted.

PLASMOLYSIS OF THE PNEUMOCOCCUS IN SODIUM CHLORIDE SOLUTIONS.

\begin{tabular}{|c|c|c|c|c|c|c|c|}
\hline 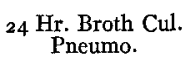 & $\begin{array}{c}25 \% \mathrm{NaCl} \\
\mathrm{H}_{2} \mathrm{O}\end{array}$ & $\begin{array}{l}0.85 \% \\
\mathrm{NaCl}\end{array}$ & Media & $\left|\begin{array}{c}\text { Approx. } \% \\
\mathrm{NaCl}_{37^{\circ}}\end{array}\right|$ & $\frac{1}{2} \mathrm{Hr}$. & $3 \mathrm{Hrs.}$ & Io Hrs. \\
\hline $\begin{array}{l}5 \mathrm{c} . c . \\
5 \\
5 \\
5\end{array}$ & $\begin{array}{l}\text { I c.c. } \\
3 \\
5 \\
\text { Io }\end{array}$ & $\begin{array}{l}9 \text { c.c. } \\
0 \\
0 \\
0\end{array}$ & $\begin{array}{l}\text { o c.c. } \\
7 \\
5 \\
0\end{array}$ & $\begin{array}{c}2.5 \% \\
5.7 \\
8.9 \\
17.0\end{array}$ & $\begin{array}{l}+ \\
+ \\
+ \\
+\end{array}$ & $\underset{“ "}{+}$ & $\begin{array}{l}+ \\
\circ * \\
\circ * \\
\circ *\end{array}$ \\
\hline
\end{tabular}

* Smears on fresh media failed to show growth; the streaks were, therefore, sterile.

Similar results were obtained in other experiments with the pneumococcus. Cultures concentrated by centrifugalization were sub-

* Of late, plasmolysis of bacterial cells in weak solutions of salts and alkalis have been extensively studied, especially in its relation to the lysis observed in immune sera; vide Fischer.9 The action of strong salt solutions on some of the saprophytic bacteria has recently been studied by Lewandowsky. ${ }^{x 7}$ 
jected to strong salt solutions; exposure to 8 or Io per cent in $\mathbf{I} 2$ hours nearly always killed the organisms; even lower percentages often sufficed, but occasionally a few living cells were found which were doubtless in the clumps or masses of cells and precipitates formed in broth cultures and were thus protected from the action of the salt solution. In some instances these living cells were virulent, as shown by the development of infection in animals inoculated with these cultures.*

It is thus evident from these studies on the plasmolysis of sodium chloride solutions that as compared with other species of pathogenic bacteria, the pneumococcus cell, aside from its capsule, is extremely susceptible, being destroyed on exposure to comparatively weak (6 per cent) solutions.

PLASMOLYSIS OF THE PNEUMOCOCCUS IN ALKALINE SOLUTIONS.

The marked susceptibility of the pneumococcus to the osmotic changes of sodium chloride solutions suggested tests of the action of alkalis, particularly as these have been used in mouth-washes.

PLASMOLYSIS OF THE PNEUMOCOCCUS IN ALKALINE SOLUTIONS.

\begin{tabular}{|c|c|c|c|c|c|c|}
\hline & & $85 \% \mathrm{NaCl}$ & Pnc. Cult. & Alkali \% & ${ }_{10}^{37^{\circ}}$ Min. & I $\frac{1}{2} \mathrm{Hr}$. \\
\hline $\begin{array}{c}\mathrm{NaHCO}_{3} \mathrm{H}_{\%} \text { in } \\
\mathrm{H}_{\mathbf{3}} \mathrm{O} \ldots \ldots \ldots \ldots\end{array}$ & $\begin{array}{l}5 \text { c.c. } \\
3 \\
1\end{array}$ & $\begin{array}{l}\text { OC.c. } \\
2 \\
4\end{array}$ & $\begin{array}{l}5 \text { c.c. } \\
5 \\
5\end{array}$ & $\begin{array}{l}2.5 \% \\
1.5 \\
0.5\end{array}$ & $\begin{array}{l}+++ \\
+++ \\
+++\end{array}$ & $\begin{array}{l}+ \text { very few colonies } \\
++ \\
+++\end{array}$ \\
\hline
\end{tabular}

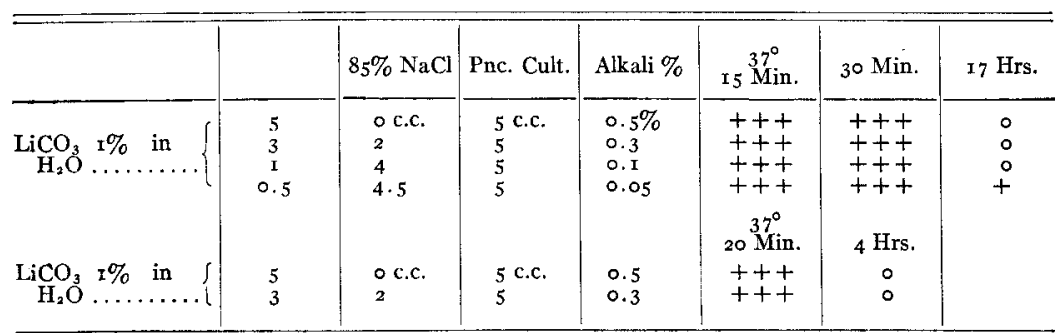

Note. -Growth on the plates is indicated by the plus $(+)$ sign; sterile plates, 0 .

* Gilbert and Carnot ${ }^{2}$ found the virulence of pneumococci growing in culture deteriorated rapidly when much smaller percentages were added to the media. My results thus seemingly fail to corroborate their findings. It may be that this is due to the different methods of experimentation, or Gilbert and Carnot's results may have been due to other conditions, particularly as the changes in virulence of pneumococci growing in artificial media are marked and variable. 
The marked action of the lithium salt led to tests of the neutral chloride of this alkali in the hope that it might prove more active than sodium chloride. Lithium chloride, however, failed to give better results than the sodium salt.

The results of these tests show that the pneumococcus is also extremely susceptible to the osmosis of alkaline solutions; and that the alkalis, owing doubtless to their different atomic composition, vary greatly in their action; but that this susceptibility to osmosis is not such as to be of practical value in destroying bacteria in the secretions of the mouth, however useful may be the addition of salts and alkalis in rendering other antiseptic solutions less injurious to the individual or more efficient in their action on bacteria.

THE ACTION OF ANTISEPTICS ON THE PNEUMOCOCCUS.

Bichloride of mercury and carbolic acid combine chemically with albuminous substances, precipitating them from solution; in fact, it is to this property that their antiseptic action is largely attributed. By the chemical union the antiseptic is so weakened, and by the precipitating action suspended bacteria caught in the coagula are protected to such an extent that the efficiency of these antiseptics in albuminous solutions is impaired. As disinfectants of sputum, carbolic acid and bichloride of mercury have proved unreliable and are now rarely used. Aside from this they are both poisons when taken internally. For these reasons neither bichloride of mercury nor carbolic acid were considered of sufficient practical value in mouth disinfection to warrant a study of their action on the pneumococcus.

Various astringent antiseptics at one time much used in the mouth have been discarded and are now considered more harmful than efficacious. The studies were thus limited to what were considered, from a practical view-point, the more promising antiseptics. Potassium chlorate, lysol, formaldehyde or formalin, the peroxide of hydrogen, and alcohol, were selected for the experiments. In order to simplify the work and at the same time secure data for subsequent comparison the tests were made on broth cultures of the pneumococcus. 
THE ACTION OF POTASSIUM CHLORATE, LYSOL, FORMALIN, HYDROGEN PEROXIDE AND ALCOHOL SOLUTIONS ON PNEUMOCOCCUS CULTURES

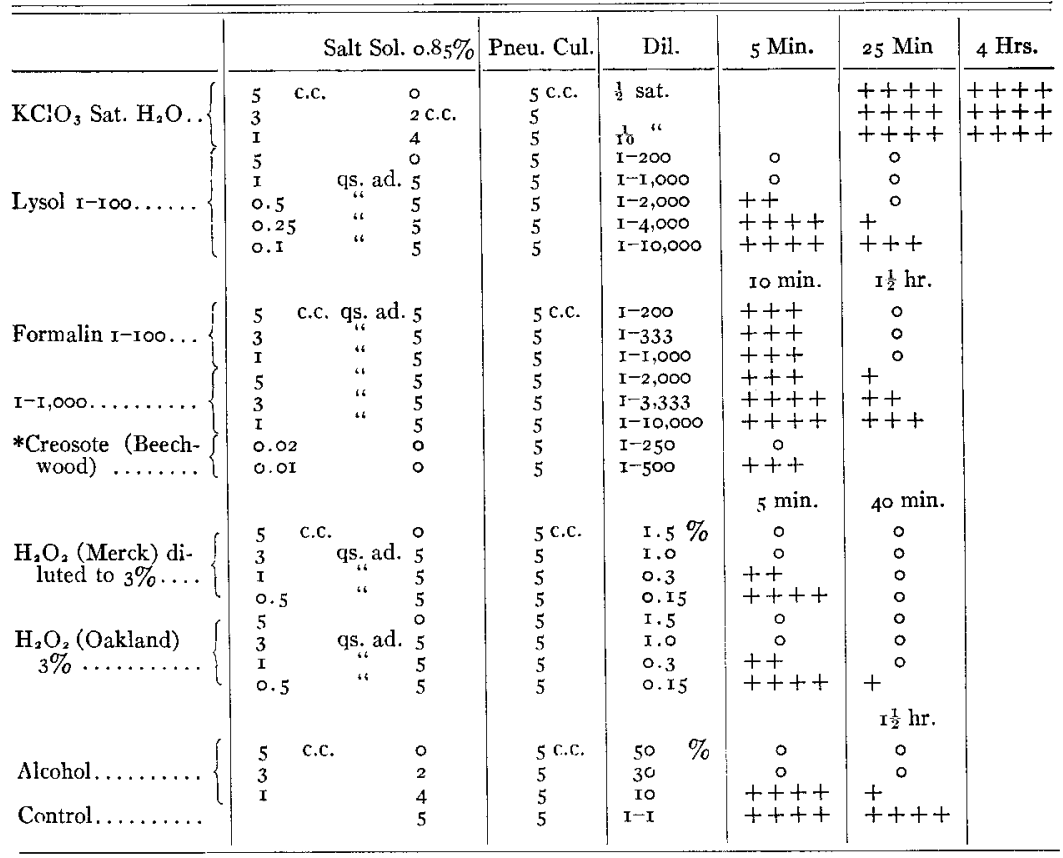

Note.-Creosote has been so strongly advocated in the treatment of many infections of the respiratory tract by many observers (vide Robinson; Med. Rec., 1906, 69, p. 529) that these tests were made of its action on the pneumococcus. From the results it is evident that Creosote in non-irritating dilutions is not sufficiently antiseptic to warrant its use in mouth washes.

In these experiments on pneumococci in broth culture, potassium chlorate proved inactive, and formalin but slowly active. On this account they were considered of little or no practical value in mouth disinfection. Lysol, hydrogen peroxide, and alcohol, however, were quick disinfectants, but their action in broth could not be accepted as any indication of their action in the mouth where the pneumococci are suspended in serous and mucous secretions. Accordingly, lysol, peroxide of hydrogen, and alcohol were tested as to their action on pneumococci in serous exudates, such as are reacily obtained from the pleuritic processes incited by the intrathoracic inoculation of virulent pneumococci in rabbits. Rabbits were inoculated with the exudate containing the antiseptics to determine any loss of virulence in the pneumococci. 


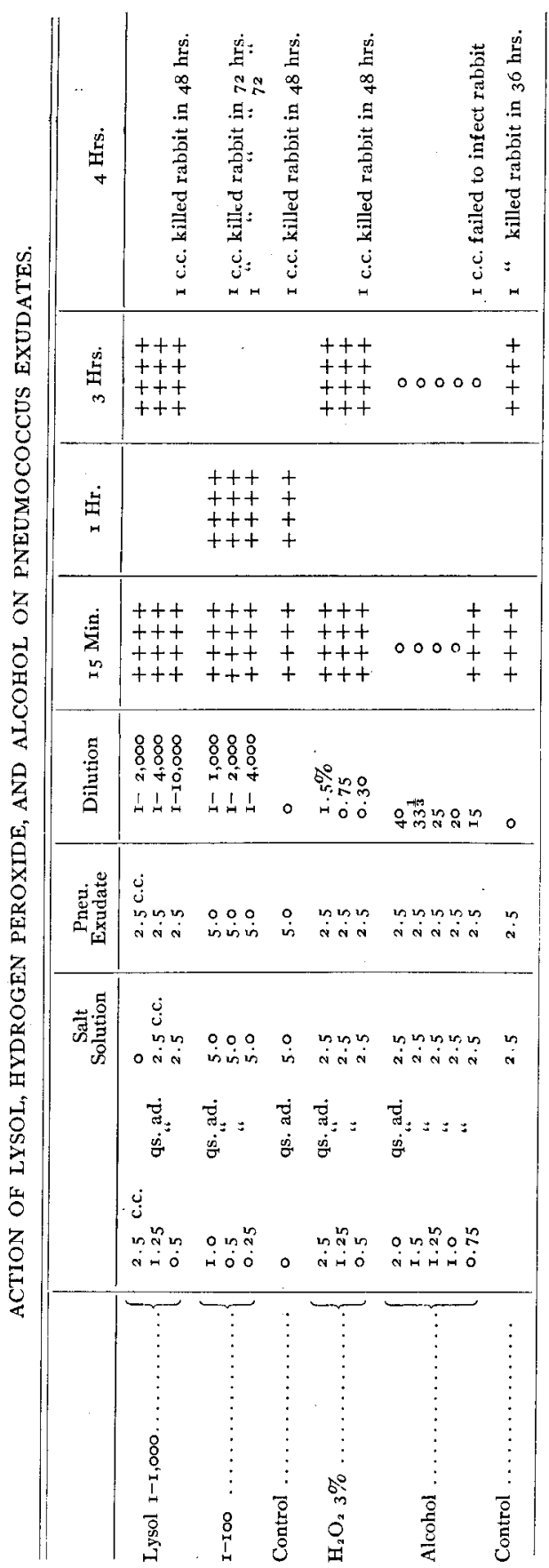


In these experiments lysol and hydrogen peroxide proved inefficient disinfectants, whereas the action of alcohol was little affected by the albuminous material of the exudate in which the pneumococci were suspended. No loss of virulence was detected in the living pneumococci after four hours' exposure.

The failure of so many of these antiseptics to act on the pneumococcus under the conditions of these experiments suggested that it might be well to study some of the much advertised commercial solutions which contain a variety of antiseptics and are extensively used as mouth-washes. Accordingly, samples of Borine, Borolyptol, Glycothymoline, Listerine, Odol, and tablets made up according to the formula of Seiler, were purchased, and tests similar to those tabulated above were made.

ACTION OF BORINE, BOROLYPTOL, GIYYCTHYMOLINE, LISTERINE, ODOL, AND SEILER'S SOLUTION ON THE PNEUMOCOCCUS.

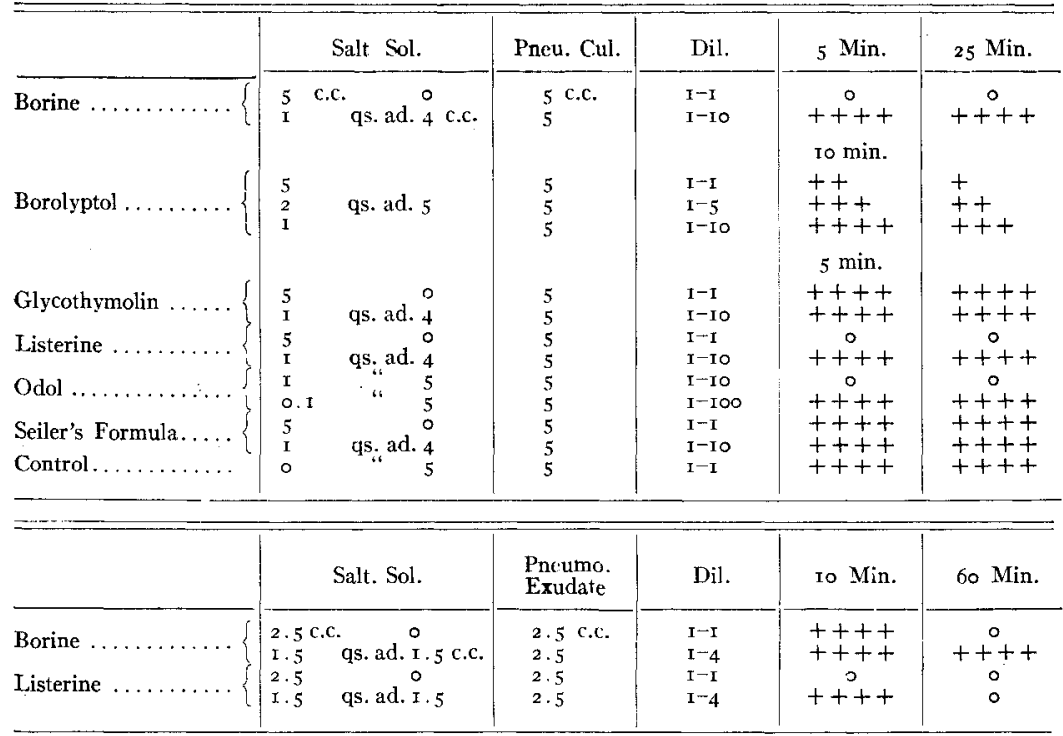

As shown by the results of these simple experiments, the failure of all these commercial solutions, is so complete as to render unnecessary further study of their inefficiency.*

By conducting the expermiental tests of the action of antiseptics on the pneumococcus along these lines-first on broth cultures and

* Some of these and other solutions prepared by commercial houses abroad have also proved inefficient when tested as mouth washes in the experiments of foreign observers; vide Pelnav, ${ }^{28}$ Miller, ${ }^{21}$ Rose ${ }^{31}$ and Greve. ${ }^{33}$ 
then on exudate obtained from infected rabbits-it was possible to simplify the study and exclude from prolonged research a long list of antiseptics. In fact, alcohol alone of all the antiseptics studied gave definite results. But lysol was not studied (in the tests with exudate) in the strongest solutions which the mouth will tolerate, so that the researches were continued with stronger solutions of this substance and alcohol. Alcohol and lysol were combined in the hope that the efficiency of one might be increased by the other. It was now possible to conduct these tests on pneumococci embedded in sputum. The pleural exudate from infected rabbits containing numerous virulent pneumococci was shaken with double the quantity of sputum. In this way an excess of the pneumococci was insured without interfering seriously with the physical or biological properties of the sputum. Sputum, as is well known, is changed physically and biologically by heat and it is impossible to filter out the contaminating bacteria, so the above method was adopted and gave excellent results. Rabbits were inoculated in these experiments to determine any loss of virulence in the pneumococci and also to control the observations made from the streak plates. The results of these tests are tabulated for convenience according to the plan used in the previous experiments.

ACTION OF ALCOHOL AND I.YSOL ON PNEUMOCOCCI IN SPUTUM.

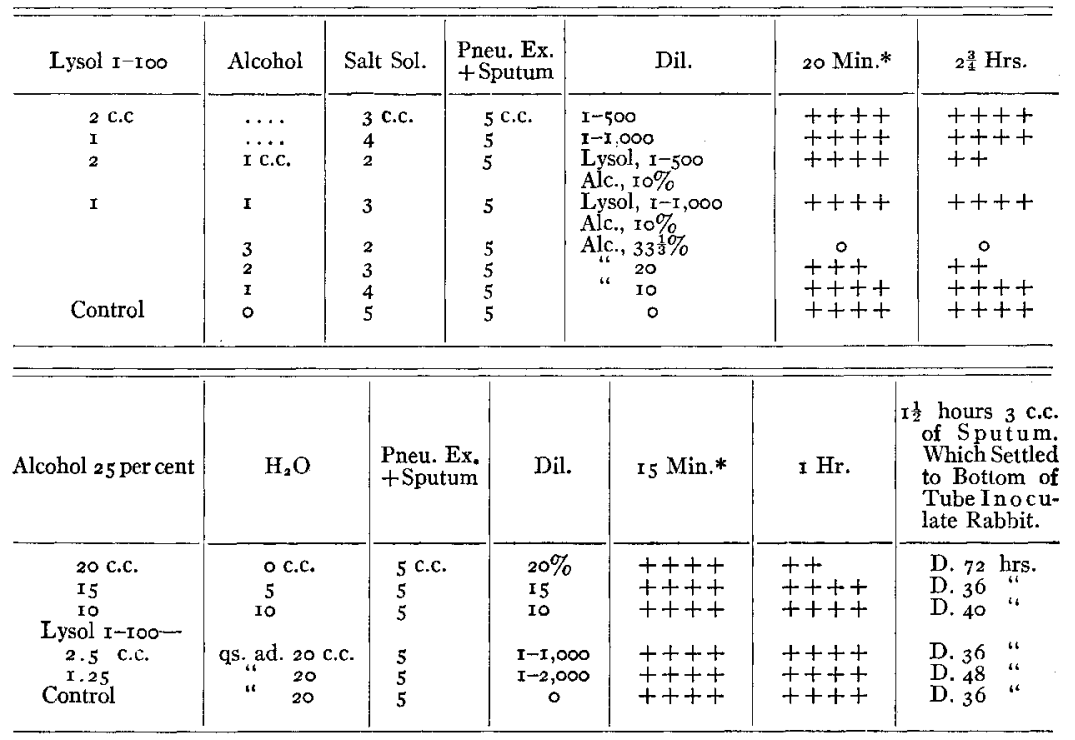

* Cultures made from shreds of sputum floating on surface. 
In these experiments lysol proved inefficient in dilution of $\mathrm{I}-500$ and there was no advantage in combining it with alcohol. For complete disinfection of pneumococcus sputum, slightly higher percentages of alcohol were required than for pneumococcus exudate. The virulence of pneumococci in sputum was not affected by either lysol or alcohol.

\section{SUMMARY OF THE EXPERIMENTAL TESTS OF ANTISEPTICS.}

From these experimental tests of the action of different antiseptics on pneumococci in broth cultures, in exudates, and in sputum, it is evident that the pneumococcus is much more susceptible to disinfection in broth than in exudates, and that in sputum it is exceptionally well protected, so much so in fact that few substances in bland dilutions have any appreciable action on either the viability or the virulence of these organisms. Hydrogen peroxide,* which quickly destroyed the organisms in broth cultures, proved worthless in the presence of the exudates, and lysol was little better. Of all the solutions studied, alcohol $\nmid$ was the least influenced by the presence of the albuminous material and detritus in the exudates or the mucus in the sputum. In fact little variation in the susceptibility of the pneumococcus could be observed in any of these alcohol tests. The antiseptic action of alcohol, therefore, was attributed not to the coagulation of cell proteids, but to osmotic changes in the pneumococcus cell, which, it may be recalled, proved exceptionally susceptible to the plasmolysis of sodium chloride solutions. Thus it is that alcohol alone withstood the test of these experiments in vitro, and alone offered any promise of solving the problem of ridding the mouth of pneumococci by means of antisepsis.

Although the results of these researches in vitro were definite, the problem in the mouth is so different and there are so many uncertain factors, that before attempting the final tests on penumonia patients, studies of the diffusion of alcoholic and other solutions

* Hydrogen peroxide has also been tested in the general problem of mouth disinfection by Rose ${ }^{3 x}$ who found 5 per cent of no practical value and 10 per cent only in a degree efficient. Rodella ${ }^{\circ}$ recom- $^{-}$ mends hydrogen peroxide as the best wash in caries of teeth, but does not give the results of his studies with it in detail.

T The experiments also show that the addition of lysol had only slight effect on the activity of the to per cent solution. 
with sputum were made in the hope that the practical efficiency of alcoholic solutions might be increased.

\section{STUDIES ON THE DIFFUSION OF ANTISEPTIC AND BLAND SOLUTIONS WITH SPUTUM.}

The various antiseptic, aqueous, alcoholic, salt, and alkaline solutions used in the previous experiments were colored by an anilin dye, carefully pipetted with equal quantities of fresh saliva in testtubes, and the line of demarkation between the two fluids noted from time to time. Owing to the clumps or shreds of mucus accurate observations could not be made and only the more obvious differences were noted. Of the aqueous solutions the diffusion of the sodium bicarbonate was most marked, but the difference was not great. Similar observations were noted for the alcoholic solutions which were slightly more pronounced than the bicarbonate.

Glycerine it was thought might render solutions more bland to the mucous membranes. Accordingly studies were made of its influence on the diffusion of solutions with saliva or sputum. A mixture of glycerine, alcohol, and water gave the best and quickest results, which were much more marked than with any of the solutions alone.

Diffusion of these solutions at different temperatures was also made and it was found that heat accelerated the diffusion and that hot solutions when used in the mouth seem to leave the mucous membranes cleaner and fresher than cold solutions. Forty-five degrees Centigrade is the highest recorded temperature which the body has attained and at the same time recovered from.* Fluids at this temperature were tried in the mouth and it was found that this was about the maximum which the mucous membrane would bear with comfort.

This maximum temperature $\left(45^{\circ} \mathrm{C}\right.$. $)$ at which mouth washes can be used is so much higher than that usually attained by the body tissues and also so much higher than that at which attenuation in cultures of virulent pneumococci has been reported (Fraenkel ${ }^{\mathrm{II}}$ ) and only $7^{\circ}$ below the thermal death-point of the organism $\left(5^{\circ} \mathrm{C}\right.$.), that a study of the effect of short exposure to this temperature on viability and virulence was made.

* Eve, Jour. Phys., 26, I900, p. IIg. 
EFFECT OF HEAT $\left(45^{\circ} \mathrm{C}\right.$.) ON THE PNEUMOCOCCUS.

The blood of a rabbit dying from pneumococcus infection was mixed with broth, and $\frac{1}{4}$ c.c. of this dilution added to tubes containing I c.c. of 2 per cent peptone. After an hour's incubation they were exposed in bath to $45^{\circ} \mathrm{C}$. Cultures and inoculations into mice were made at stated intervals.

\begin{tabular}{|c|c|c|c|}
\hline $45^{\circ}$ & Plate 24 Hrs. Growth & Mouse Inoculation & Result \\
\hline 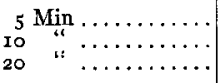 & $\begin{array}{l}++++ \\
++++ \\
++++\end{array}$ & 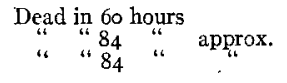 & $\begin{array}{c}\text { Pneumo. infect. } \\
\text { " }\end{array}$ \\
\hline
\end{tabular}

However valuable for physical or physiological reasons the use of hot mouth washes may be, the temperatures at which such solutions can be used have practically no effect on either the virulence or the viability of the pneumococcus.

SUMMARY OF THE TESTS OF DIFFUSION AND THE VALUE OF HEAT.

The results of these observations on the diffusion of different solutions with saliva or sputum suggest that the addition of sodium chloride and sodium bicarbonate in bland quantities may facilitate the diffusion of these solutions with the secretions, but that the best results are secured when these solutions are used hot. By the addition of glycerin the diffusion of such solutions with the secretions of the mouth is greatly accelerated.

For the practical tests, therefore, the bland simple solutions containing $\mathrm{NaCl} 0.5$ per cent, sodium bicarbonate 0.25 per cent, were used hot. The alcoholic solutions, on the other hand, contained alcohol 30 per cent, the lowest percentage which could safely be relied on to destroy the pneumococci in sputum, and glycerin to per cent in addition to the isotonic quantities of sodium chloride and bicarbonate used in the bland solutions. Spirits of chloroform and oil of wintergreen were also used to disguise the taste of the alcohol. With these solutions the practical studies were conducted on pneumonia patients: the bland solution with a view of determining the effect of simple rinsing of the mouth, diluting and removing the secretions with the bacteria; the alcoholic solutions with a view of determining the value of disinfection. In health the pneumococci 
are practically confined to the mouth or upper air passages. In pneumonia, virulent pneumococci are being continually coughed up from the lung. The pneumonia patient, however, sooner or later reaches a stage when living pneumococci are no longer coughed up from the lung. This stage is doubtless more quickly reached in those recovering by crises, and an attempt was made to secure some definite data on this point by a comparative study of the sputa from the mouth with that from the lungs or bronchi. Contaminations from the mouth, however, could not be excluded, so the results were not significant. In tuberculosis, clumps of exudate from the lung may be studied by Kitasato's method of repeated washing, but with the material obtained from pneumonia patients this was not practicable.

\section{PRACTICAL TESTS OF MOUTH CLEANSING AND DISINFECTION IN PNEUMONIA.}

Through the kindness of Dr. G. L. Peabody, cases of pneumonia at the Roosevelt Hospital, before and after the crisis and also during lysis, were given six ounces of the simple bland wash for rinsing the mouth and gargling the pharynx. For four days specimens of the secretion were collected in the morning before the mouth cleansing, after the mouth cleansing, and following this specimens of sputa were coughed up from the lungs and bronchi. Morphological examinations of these specimens were made but proved unsatisfactory and were shortly abandoned. Animal inoculation, however, proved quite sufficient. An eighth to a quarter of a cubic centimeter of the sputum was injected subcutaneously into mice. The results may be very briefly stated, for of these specimens, in all 40 , none failed to kill mice by pneumococcus infection, and the animals died at regular and uniform intervals. It was thus definitely determined that rinsing and gargling the mouth and pharynx, as practiced in the hospital routine, is a useless procedure in so far as getting rid of the virulent pneumococci is concerned. Similar results were obtained in tests conducted on healthy individuals. Occasionally it was noted that an irritation of the mucous membrane followed by varying inflammatory conditions developed after this energetic mouth cleansing with the saline solutions.

Through the kindness of Dr. William $\mathrm{H}$. Thomson, a series of 
practical tests of the disinfecting action of the alcohol mouth wash* was conducted on cases of pneumonia at the Roosevelt Hospital. The tests were made in the same way as in the previous experiments, in which the bland saline solutions were used for the mouth cleansing. Larger quantities of sputum were used in the inoculations; each mouse received approximately 0.5 c.c. These results may also be briefly stated, for the specimens, $3^{2}$ in all, never failed to show the presence of virulent pneumococci. The animals, however, in spite of the larger quantities of sputum inoculated, died at more irregular intervals than in the tests made with the bland saline solutions. In one case this was particularly marked. The two controls from this patient taken before the wash was used died in three and three and one-half days; subsequent controls in seven, eight, and four days; the tests in thirteen, eight, nine, and five days respectively. It was thus definitely established that disinfection of the mouth

* For convenience in the hospital practice the solution was so made up that the addition of water in equal parts gave the desired strength. The flavorings of spts. of chloroform and oil of wintergreen lose their strength after keeping a few weeks, so that it may be wise to guard against this by the substitution of other flavoring agents.

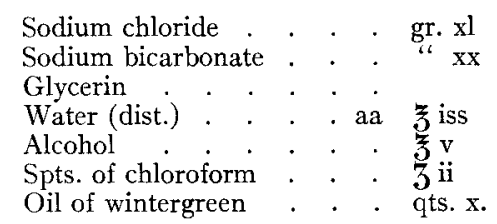

Dilute with water in equal parts.

Owing to the sweet taste and the evaporation of the chloroform and oil of wintergreen this solution has not proved as satisfactory in private practice as those containing other flavoring agents. Although it was found that the solution may be varied to suit the taste of the patient by the use of different flavoring agents, the following formula has given, in my experience, the best results:

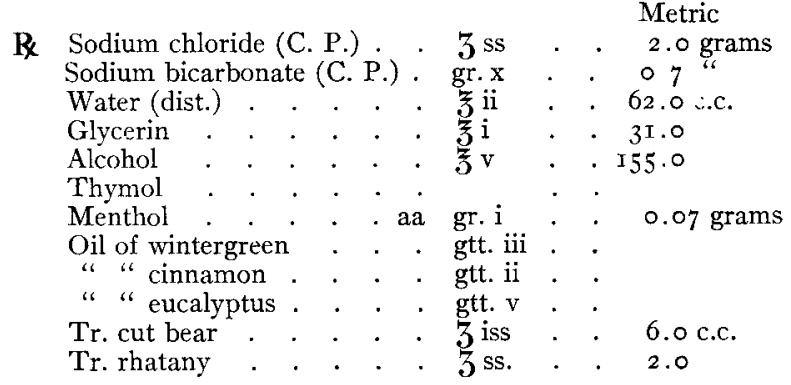

M. Sig. Dilute with water equal parts.

In preparing these solutions the salts should be dissolved in the water before adding alcohol. Even when carefully made up a cloudiness or a precipitate may appear in the solution, especially in those containing the tincture of rhatany By adding two or three of the flavoring oils a less pronounced taste is obtained than when only one is used. 
and pharynx by means of antiseptic mouth washes, as practiced in the hospital routine of pneumonia patients is incomplete.

Similar results were obtained in the practical tests conducted on healthy individuals, except in one instance where for 48 hours, so far as could be determined by animal inoculation, complete disinfection of the pneumococci in the secretion was secured with the alcohol solution. As compared with the experiments with the bland saline solutions, no irritation or inflammation of the mucous membrane followed the use of this alcoholic mouth wash.

Personal experience with the two methods, the simple and the antiseptic, yielded unexpected results. During the use of the bland salt solution pneumococci were always found by the inoculation of mice with the secretion. After the substitution of the alcohol antiseptic solution pneumococci, except occasionally at first, have not been obtained from the secretion under normal conditions. It thus appears that removing and disinfecting the contaminated secretions from the more accessible parts of the mouth with the alcohol wash may in time accomplish the elimination of pneumococci from the secretions of healthy persons.

By using an efficient antiseptic wash which is non-irritating, large numbers of virulent pneumococci, those present in the secretions and some of those remaining in the mouth, are destroyed, and the exposed mucous membrane is less apt to become infected; thus the danger, not only to the individual but to his fellows, from the infectious secretions, is materially lessened as compared with the cleansing with bland saline solutions having no antiseptic action. Furthermore, aside from its antiseptic action, the alcohol formula proved quite as bland and more effective in the mechanical cleansing of the mouth than the simple isotonic salt solutions; the secretions were more quickly removed from the mucous membranes and teeth; the irritation of simple alcohol solutions was relieved by the addition of glycerin and salts to such an extent that a mild beneficial stimulation, without injurious desiccation, was all that was experienced, and this was quickly followed by an increased flow of fresh secretion of comparatively pure mucus, which replaced the old contaminated saliva and sputa in the mouth and pharynx.

Thus it is that although complete disinfection of the mouth in 
pneumonia is uncertain, the best results were secured by using for mouth cleansing an efficient antiseptic, such as alcohol, rendered bland and non-irritating.

\section{SUMMARY AND CONCLUSIONS.}

Although mouth cleansing has long been practiced, and although previous study of mouth disinfection has shown that complete disinfection is impossible and suggested many of the serious difficulties encountered in the general problem, the results of all this experience failed to determine accurately the best procedures or discriminate definitely between the efficient and the inefficient, even harmful, antiseptics. Similarly the results of the present studies show that complete disinfection of the mouth is impossible, but from the tests made in the various experiments the practical value of many of the antiseptic procedures commonly employed in mouth disinfection was accurately determined.

It was found that pneumococci, as compared with other pathogenic bacteria, are extremely susceptible to the plasmolytic action of saline and alkaline solutions and also to the antiseptics which act in this way. But the susceptibility to antiseptics in general varies greatly and especially under different conditions. In broth media the pneumococci are readily destroyed; in exudates the albuminous material and detritus interferes with the action of many antiseptics; in sputum, disinfection by harmless solutions is extremely difficult.

Of all the commercial solutions studied-listerine, borine, borolyptol glycothymoline, odol, and Seiler's solution-none proved efficient when tested on pneumococci under the conditions most favorable for their action. Formalin, lysol, and hydrogen peroxide, failed to act on the pneumococcus in exudates. In short, alcohol alone of all the antiseptics studied proved efficient when tested on the pneumococci under all the conditions of the experiments.

Observations on the diffusion of the different solutions with the secretions of the mouth under different conditions showed that the presence of salts in isotonic quantities and alkalis was of positive, if slight, value. The rapid diffusion obtained with alcoholic solutions was greatly accelerated by the addition of glycerin. Finally, the results of these experiments suggested the use of hot solutions. 
As shown by the practical studies, cleansing the mouth with simple isotonic salt solution removes a certain amount of the secretion and with it some of the infectious material, but does not destroy the bacteria. With the alcohol wash many of the bacteria are destroyed, the contaminated secretions are more rapidly removed and at the same time disinfected, and, finally, the natural resources of the tissues are more safely and efficiently aided in the elimination of the infectious material. It was thus determined that alcohol solutions containing glycerin and salts in bland quantities were in every particular more efficient than any of the washes hitherto recommended for mouth cleansing or disinfection; 30 per cent of alcohol being the strongest that can be comfortably and habitually used in the mouth and the weakest that will give reliable disinfection.

From the hygienic standpoint the secretions of the mouth constitute the chief, if not the only, source of respiratory infection and the infectious material is transformed from one person to another; in some instances through the air as from sneezing or coughing, but to a much larger and more serious extent, directly by personal contact or the use in common of the various accessories of life. In crowded communities and during seasons of the year when people are huddled closely together in narrow quarters, the vicious cycles by which the dissemination of the infectious material is fostered involve nearly every individual. Under such conditions the precautions and regulations within the jurisdiction of the health authorities, so successfully adopted with other infectious diseases, are obviously inadequate, and the responsible burden of alleviating or controlling the spread of the respiratory diseases rests largely upon the individual.

Whether it be for purposes of cleanliness or as a wise precaution in the care and preservation of the teeth, mouth cleansing of some sort will always be practiced. The present researches with reasonable precision show that not only is the simple cleansing best effected with bland alcoholic solutions, but as disinfectants in the mouth these solutions, of all those studied, alone possess practical value.

I wish, particularly, to express my indebtedness to Professor $\mathrm{T}$. Mitchell Prudden for his suggestions and for his criticism.

BIBLIOGRAPHY.

I. ARLoING. Jour. de physiol. et de path. gen., I902, 4, p. $29 \mathrm{I}$.

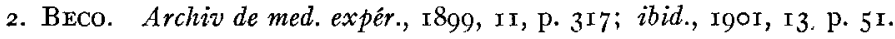




\section{Mouth Disinfection in Pneumonia}

3. v. BEsser. Zieglers Beiträge, $1889,6, \mathrm{p} .35^{\mathrm{I}-62}$.

4. Bezancon et Griffon. Soc. med. des Hopitaux, I898, Apr. I5.

5. BonHoff. Centralb. f. Bact., r902, 32, p. 641.

6. Buerger. Jour. Exper. Med., I905, 7, p. 545.

7. Danielshon and Hess. Deuisch. med. Wchnschr., 1902, 28, p. 662.

8. Engels. Hand Disinfection, I905, G. Fischer, Jena.

9. Fischer. Zeitschr. f. Hyg., I900, 35, p. I.

IO. Flecksedor. Centralbl. f. inn. Med., I905, 26, p. 4I.

I I. Fraenkel. Zeitschr. f. klin. Med., I886, ro, pp. 4I9, 420.

12. Gilbert et Carnot. Compt. rend. de Soc. de biol., i9o4, p. 925.

13. Greve. Prevention of Diseases of the Teeth and Mouth, p. 769, Vol. II of The Prevention of Disease; translation published by Funk and Wagnalls, I9०3.

I4. Hiss. Jour. Exper. Med., I905, 7, p. 58 I.

I5. Hopkins. Internat. Dental Jour., I903, Aug.

16. Kolle u. WASSERMan. Handbuch der Pathogen Mikroorganismen, 1903, 2, p. 779 .

17. Lewandowsky. Archiv f. Hyg., т904, 49, p. 47.

18. LongCOPE AND Fox. Jour. Exper. Med., 1905, 7, p. 430.

I9. Miller. Dental Cosmos, 189 I, 33, p. 253.

20. Miller. Microorganisms of the Human Mouth, 1890, p. 205.

21. Miller. Ibid., pp. 225-36; Lehrbuch der Conservierenden Zahnheilkunde, I898, Leipzig, pp. 440-43.

22. Monier. Ref. Bull l'Inst. Past., I904, 2, p. 857.

23. Morisiant. Arch. di. ost. e. Ginec, 1897,4 , p. I33.

24. Netter. Soc. de biol., I897, Nov. 29; Traité de Méd. (Bouchard et Brissaud) I9OI, 6, pp. $455,486$.

25. Neumann. Zeitschr. f. Hyg., I902, 40, p. 33 .

26. Park. Biggs, Park, And Beebe, Report on Bact. Investigation and Diag., of Dipththeria, Health Dept., City of New York, 1895 .

27. Park AND Williams. Jour. Exper. Med., I905, 7, p. 407.

28. Pelnav. Wien. klin. Rundschau, 1902, pp. 197 and 222.

29. Ritter. Weyl. Handbuch der Hygiene, Supplement 2, I901, "Zahn und Mund Hygiene," pp. 23I and 238.

3o. Rodella. Centralbl. f. Bakt,, I904, Orig. 37, pp. 314-I7.

31. Rose. Zeitschr. f. Hyg., I901, 36, p. r6I.

32. Schasffer. Therapeutische Monatshefte, I904, Nov.

33. Steffen. Centralbl. f. Bakt., I895, 18, p. I64; with Grawitz, Berl. klin. Wchnschr., 1894, 3. . P. 4 I9.

34. Stroganofr, Centralbl. f. Gynäk., I893, No. 40.

35. Sturtz. Zeitschr. f. klin. Med., I904, 52, pp. 422-69.

36. Thomson and Hewlett. Medical and Surgical Trans., I895, p. 239; Brit. Med. Jour., I 896 , I, p. 137 .

37. Walthard. Centralbl. ;. Bakt., I895, I7, p. 3II; Arch.f. Gynäk., 48, pp. 233-44.

38. WEIGL. Archiv f. Hyg., I902, 44, p. 273.

39. Wirgin. Zeitschr. f. Hyg., 1902, 40, p. 307; ibid., 1904, 46, p. I49.

40. Wood. Jour. Exper. Med., I905, 7, p. 621, 622.

4I. Wurtz et Lemoyez. Compt. rend. de Soc. de biol., r894. 